\title{
Analysis of profile of childhood kerosene poisoning in a tertiary care medical college hospital
}

\author{
Sunilkumar MN 1 , Parvathy $\mathrm{VK}^{2}$ \\ ${ }^{1}$ Dr Menon Narayanankutty Sunilkumar, Department of Pediatrics, Amala Institute of Medical Sciences, Amala Nagar, \\ Thrissur, Kerala, India, ${ }^{2}$ Dr Vadakut Krishnan Parvathy, Amala Institute of Medical Sciences, Amala Nagar, Thrissur, \\ Kerala, India
}

Address for Correspondence: Dr. Menon Narayanankutty Sunilkumar, Assistant Professor, Department of Pediatrics, Amala Institute of Medical Sciences, Amala Nagar, Thrissur, Kerala, India, E-mail: sunilsree99@ yahoo.co.in

\begin{abstract}
Background: Children are very vulnerable to acute accidental poisoning. One of the most important poisoning in children is accidental ingestion of kerosene which is a common household substance. Its prevention plays a major role in reducing its morbidity and mortality in children. Objective: To understand the profile of accidental kerosene poisoning in children with special reference to symptoms, complications, radiological changes, course and outcome after treatment. Materials and Methods: Children hospitalized with acute poisoning at the paediatric intensive care unit (PICU) between January $1^{\text {st }} 2010$ and December $31^{\text {st }} 2015$ were retrospectively evaluated from hospital records. A detailed history was taken using the proforma having special reference to age, sex, poisoning agents and route of intake, time of admission of the poisoned patients,socio- economic status of the family and cases with acute kerosene poisoning (AKP) were analysed. Results: In the PICU out of a total of 5806 patients admitted, $401(6.9 \%)$ were due to acute poisoning . Among them AKP was noted in 91 (22.7\%) patients and was second only to pharmaceutical medicine poisoning in 128 $(28.7 \%)$ cases. All the children were admitted to the PICU, but most only required supportive care. There was no mortality following AKP during the study period. Conclusion: All paediatric age groups are at risk of AKP. Most children suffer due to unintentional poisoning because of easy availability of kerosene in their house itself. As AKP is preventable it must be given due importance in health control programs at all levels of health care.
\end{abstract}

Key words: Acute child poisoning, Unintentional, Hydrocarbons, Paraffin, Acute Kerosene poisoning, Pneumonitis

\section{Introduction}

Acute poisoning in children requires emergency care and is an important health hazard [1]. The incidence of accidental poisoning (AP) in children is about $7-8 \%$ as in many studies [ 2 ]. Acute kerosene poisoning (AKP) is very common in the developing countries $[1,2]$. The young infant becomes highly vulnerable to accidental poisoning because of their ignorance and curiosity to explore new things. Hydrocarbons (HC) are implicated in most of these AP. The commonly encountered poisoning in the group of $\mathrm{HC}$ are volatile substances such as petrol, diesel, turpentine and kerosene. HC poisoning account for about $5 \%$ of all AP and $25 \%$ of all fatal ingestions in children of less than five years of age [3]. Kerosene is a hydrocarbon product of petroleum distillate, made up of paraffin and

Manuscript received: $3^{\text {rd }}$ March 2016 Reviewed: $12^{\text {th }}$ March 2016

Author Corrected; $24^{\text {th }}$ March 2016

Accepted for Publication: $12^{\text {th }}$ April 2016 naphthenes and is otherwise known as paraffin. AKP presents as involvement of mainly the respiratory and central nervous systems. The gastro-intestinal tract is also commonly but mildly involved. Rarely, other systems may be affected such as the kidneys and myocardium [4]. This study was conducted to understand the profile of kerosene poisoning in children with special reference to the age of children, issues in the clinical presentation, investigations and timely management.

\section{Materials and Methods}

The medical college in Thrissur district is almost in the centre of Kerala state and receives patients from nearby four districts. In this study children hospitalized with acute poisoning at the paediatric intensive care unit (PICU) between January $1^{\text {st }} 2010$ and December $31^{\text {st }}$ 
2015 were retrospectively evaluated from hospital records. A thorough history was taken using the proforma having special reference to age, sex, poisoning agents and route of intake, time of admission of the poisoned patients after ingestion, socioeconomic status of the family (according to the modified Kuppuswamy scale). In this retrospective study necessary investigations including complete hemogram, chest $x$ ray were done in cases with AKP. Blood gas analysis was also done in hypoxic patients following AKP. As most of the patients were from the villages and towns near to the medical college none of them had any toxicological analysis report. Inclusion criteria of the study took into consideration those with definite history of accidental kerosene ingestion and also other hydrocarbons such as petrol, diesel, turpentine. All babies below 1 year age, developmentally delayed children, having associated diseases like chronic debilitating encephalopathies and neuropathies, neuro degenerative diseases and AP with other substances were excluded. Profile of paediatric population with AKP, their symptoms, complications, radiological changes after ingestion and outcome after treatment were analyzed. The study design was approved by Institutional Ethics Research Committee.

\section{Results}

During the study period a total number of 5806 patients were admitted in the PICU and 401 (6.9\%) admissions were due to acute poisoning. As regard with the etiological agents involved, sixty two products were identified as various causes of AP. AP due to drugs and medicines poisoning was noted in $128(28.7 \%)$ children. This was followed by ingestion of kerosene in $91(22.7 \%)$ cases.

So the problem of AKP was significant. Among the children with AP majority, $126(31.2 \%)$ of these were between 2 to 3 years of age. Male children were $65.8 \%$ and females $34.2 \%$. Among the children with AKP majority 47(51.6\% ) were also in the age group between 2 to 3 years. (Table 1).

Male children with AKP were $61.5 \%$ and females 38.5\%. Among the less than 1 year group included an 8 month old, 9 and 10 month old infants with AKP.

According to the social status majority belonged to lower socio-economic status $72(79.1 \%)$ and were from the villages and rural areas. The kerosene was kept in the home and was routinely used for cooking, heating and lighting the house. More than $90 \%$ of the AKP had vomiting and nausea as the initial symptom after exposure.

The common symptoms children had were vomiting and nausea 73 ( $80.2 \%)$, coughing $75(82.4 \%)$, fever 63(69.2\%) tachypnoea 23 ( $25.3 \%$ ) fever 63(69.2\%) grunting 19(36.3\%), restlessness 21 (23.1\%) drowsiness $11(12.1 \%)$, cyanosis $1(1.1 \%)$ there were no symptoms in 16 ( $17.6 \%)$ children.

One child had severe pneumonitis and had abdominal pain, tachypnea, central cyanosis, drowsiness, along with grunting and was very sick as he presented late after ingestion of kerosene (Table 2).

The incidence of AKP was highest in the months of February 14 (15.4\%), April 24(26.4\%), May 14 (15.4\% ) and June $10(11 \%)$ in these five years of study.

\section{Table 1: Distribution of age}

\begin{tabular}{|c|l|l|l|}
\hline S. No & Age in years & Total no of children $(\mathbf{n = 9 1 )}$ & $\mathbf{\%}$ \\
\hline 1. & Less than 1 year & 3 & $3.3 \%$ \\
\hline 2. & 1 to 2 years & 31 & $34.1 \%$ \\
\hline 3. & 2 to 3 years & 47 & $51.6 \%$ \\
\hline 4. & 3 to 4 years & 5 & $5.5 \%$ \\
\hline 5. & 4 to 5 years & 2 & $2.2 \%$ \\
\hline 6. & Beyond 5 Years & 3 & $3.3 \%$ \\
\hline
\end{tabular}


Table 2: Clinical manifestations of kerosene ingestion among 91 children

\begin{tabular}{|c|l|l|l|}
\hline S. No & Symptoms & No of Patients & $\mathbf{( \% )}$ \\
\hline 1. & vomiting and nausea & 73 & $80.2 \%$ \\
\hline 2. & coughing & 75 & $82.4 \%$ \\
\hline 3. & fever & 63 & $69.2 \%$ \\
\hline 4. & grunting & 19 & $36.3 \%$ \\
\hline 5. & restlessness & 21 & $23.1 \%$ \\
\hline 6. & drowsiness & 11 & $12.1 \%$ \\
\hline 7. & cyanosis & 1 & $1.1 \%$ \\
\hline 8. & No symptoms & 16 & $12.1 \%$ \\
\hline & Total & $\mathbf{9 1}$ & $\mathbf{9 1}$ \\
\hline
\end{tabular}

Table -3: Involvement of the lungs in chest rays of children with AKP

\begin{tabular}{|c|l|l|l|}
\hline S.No & Lung involvement in c-xrays & Number of c-xrays & $\mathbf{( \% )}$ \\
\hline 1. & Right-sided lung & 51 & $56 \%$ \\
\hline 2. & Left sided lung & 13 & $14 \%$ \\
\hline 3. & Bilaterally & 11 & $12 \%$ \\
\hline 4. & Normal & 16 & $18 \%$ \\
\hline
\end{tabular}

All the patients were admitted to the PICU. Complete hemogram done revealed leukocytosis in about $69 \%$ cases. Chest $\mathrm{x}$ ray were done in cases with AKP. 16 were normal and 75 x-rays had varying degrees of infiltrations in the lung fields. The infiltrations in the majority were right-sided in $51 \mathrm{x}$-rays, $13 \mathrm{x}$-rays had left sided lung lesions and in $11 \mathrm{x}$-rays it was bilaterally seen (Table 3). Varying degrees of lower lobe consolidation were seen more than the upper lobes in the $\mathrm{x}$ rays. Most only required supportive care and these children were properly monitored. The children were immediately changed the clothes with kerosene spillage and bathed with soap and water to decontaminate skin and hair. The caretakers who were with the children were also advised to change their clothes and towels contaminated with vomitus containing kerosene. The supportive care given in the form of oxygen inhalation, proper hydration, antipyretics, antiemetics and intravenous antibiotics started after the x-ray showed infiltrations and consolidation .Gastric lavage was not done in any of these children. Once the child was stabilised in the PICU the children were shifted to the paediatric wards and managed. Among these 401 ACPs only 2 children expired but none with AKP. Children with AKP were regularly followed in the outpatient clinic. $100 \%$ came in the first week after discharge and $75 \%$ came later on as advised in the symptomatic group.

\section{Discussion}

Poisoning is the fourth leading cause of mortality and morbidity following road traffic accident, burns and drowning [1]. Children are very vulnerable and the paediatric population below the age of five years constitute about $15 \%$ of unintentional poisoning related deaths $[2,3]$. The children are inquisitive and often are poisoned accidentally when they ingest them orally. Male children with accidental poisoning (AP) were $65.8 \%$ and females $34.2 \%$ in our study [4]

Among the APs Acute Kerosene poisoning (AKP) is a major problem around the world and is an alarming health issue to any health care facility. Kerosene was the second commonest agent involved as a cause of AP in our study. It has been reported as the commonest substance involved in accidental childhood poisoning in India as well [5]. Also other studies from the developing countries in Asia (India, Malaysia) \& Africa (Nigeria) have mentioned the prevalence of this hydrocarbon ingestion.[6,7,8,] .Kerosene oil is used as a fuel for cooking and other purposes in most of the developing countries. It is sold sometimes openly and parents store them in medicine bottles, household containers or soft drink bottles. Children have an easy access in the kitchen 
and unintentionally consume them. This is substantially due to an increasingly rapid rate of industrialization with an increase in the number and types of chemicals available worldwide [9]. Pertaining data and studies revealed that children under five years of age are particularly at risk from accidental AP [5-8].

Kerosene or paraffin is included under the group of hydrocarbons. Among the chemical substances products with high volatility, low viscosity and low surface tension are more likely to be aspirated and result in pulmonary injury. Lower viscosity promotes penetration into more distal airways and lower surface tension increases spread over a larger area of lung tissue [10]. Volatile hydrocarbons may reach the CNS through the blood stream after inhalation or ingestion $[10,11]$. It is usually difficult to be certain about the amount of kerosene that has been ingested by a child, because the amount stored is usually unknown and some is usually spilled. In our study also the parents and care takers who were with the children when they were hospitalised could not quantify the amount of kerosene in the containers. According to the social status majority belonged to lower socio-economic status 305 (76.2\%) and were from the villages and rural areas with a similar data of $72.3 \%$ has been reported from a referral centre in India[5].

The AKP can affect the respiratory system and can develop respiratory complications such as chemical pneumonitis, pneumomediastinum, pneumothorax and subcutaneous emphysema as a result of aspiration [12]. Aspiration frequently occurs, either initially or a mildlydelayed fashion as the patient coughs or vomits, thereby resulting in pulmonary events. Once aspirated, kerosene can create a severe pneumonitis. Chemical pneumonitis results from a direct toxic affect on the lung parenchyma. Type II pneumocytes are the cells most affected and this ultimately leads to altered surfactant production and function. The end result of hydrocarbon aspiration is interstitial inflammation, intra-alveolar haemorrhage and oedema, hyperaemia, bronchial necrosis and vascular necrosis. Most cases often present with tachypnoea and hypoxia, requiring oxygen supplementation. It has been demonstrated clearly in animal experiments that pulmonary injury following ingestion results from aspiration and not from gastrointestinal absorption [13]. These conclusions are consistent with the clinical observation that manifestations rapidly follow ingestion. The gasping and choking which frequently accompany ingestion predispose to aspiration. Vomiting, whether spontaneous or induced, increases the risk of aspiration and adds to the severity of pneumonia [14]. Following ingestion, there is little absorption from the gastrointestinal tract to the systemic circulation. Because only small amounts are ingested by children it is concluded that CNS manifestations seen with kerosene ingestion are due to hypoxia and acidosis from damage to the lungs and not due to systemic absorption [15].These findings are consistent with the clinical observations that significant CNS complications are usually seen in association with pulmonary manifestations. Among the children with AKP majority 47(51.6\% ) were also in the age group between 2 to 3 years (Table 1). Male children with AKP were $61.5 \%$ and females $38.5 \%$. Among the less than 1 year group included an 8 month old, 9 and 10 month old infants with AKP. Nagi AA and Abdullah in 1995 demonstrated kerosene intoxication through skin. Absorption in a seven-dayold baby and had convulsions and was saved due to timely management and good history taking [16].

The incidence of AKP was highest in the months of February 14 (15.4\%),April 24(26.4\% ) , May 14 $(15.4 \%)$ and June $10(11 \%)$ in these five years of study. During this period in Kerala there is hot season and the problem is aggravated by power failure due to lack of rains in the state. This adds to the problem of increased kerosene consumption in these families which use them for multiple purposes and other studies have also have revealed seasonal incidence of AKP $[5,12,16,17]$. Ingestion was the most common route in all cases in the study and was similar in other studies[4,17].The AKP in our study was unintentional poisoning as in other studies [17] but only 2children above 10 years had intentionally consumed kerosene in our study. These children were fortunately rescued by timely management. Intentional intake is reported in many studies $[1,3,17]$.

Usually the mother or the care taker might have found the child with the bottle containing kerosene. The family might have stored kerosene usually in a medicine bottle very often. The infant is found with his mouth and often his clothes smelling of kerosene and has cough and nausea. Most of the cases in our study had admission within 4 hours of ingestion of kerosene. They soon develop fever with grunting and become tachypneic with clinical evidence of pneumonitis. The common symptoms were vomiting and nausea, coughing, fever, tachypnoea, grunting, restlessness. There were no symptoms in $16(17.6 \%)$ children. These were in similarity in other studies as well [4-8,14-16]. 
One child had severe pneumonitis and had abdominal pain, tachypnea, central cyanosis, drowsiness, along with grunting and was very sick as he presented late about 12 hours after ingestion of kerosene. Most of the cases had involvement of the respiratory system as in other studies. $69 \%$ cases had leukocytosis in complete hemogram as reported in other studies as well $[4-8,14-$ 16]. Chest $x$ ray were done in all cases with AKP. 16 were normal and 75 x-rays had varying degrees of infiltrations in the lung fields. The infiltrations in the majority were right-sided. Varying degrees of lower lobe consolidation were seen more than the upper lobes in the X-rays. 16 children after AKP had normal chest $\mathrm{X}$-rays and were asymptomatic probably as they had very minimal ingestion of kerosene. Blood gas analysis was also done in the hypoxic, cyanosed sick child following AKP. The x-rays findings correlated with other studies [4-6,14-16,18].

All the children in the study with AKP were treated symptomatically with oxygen, intravenous fluid and antipyretics were used as needed. There is a controversy in the management of cases with AKP with gastric lavage (GL).Many observations have proved that pneumonitis may occur as a result of gastro-intestinal absorption of kerosene during a GL. In 1963 itself Gerarde postulated that the combination of low viscosity and low surface tension is primarly responsible for the chemical pneumonitis caused by the aspiration of light hydrocarbons such as kerosene [10]. Recent guidelines recommend GL should be reserved for those cases where there has been ingestion of large amounts of kerosene [14-16,19]. In none of our 91 cases was there any such indication for a GL as in other studies [4-6,14-16]. Most only required supportive care and these children were properly monitored. The children were immediately changed the clothes with kerosene spillage and bathed with soap and water to decontaminate skin and hair. The caretakers who were with the children were also advised to change their clothes and towels contaminated with vomitus containing kerosene. The supportive care given in the form of oxygen inhalation, proper hydration, antipyretics, antiemetics and intravenous antibiotics (commonly used was co- amoxyclav as injection) started after the x-ray showed infiltrations and consolidation. Gastric lavage was not done in any of these children. Once the child was stabilised in the PICU the children were shifted to the paediatric wards and managed. None of the study population had convulsions or were comatose as mentioned in other studies $[4,16,20]$. Among these 401 APs only 2 children expired but none with AKP. Children with AKP were regularly followed in the outpatient clinic. $100 \%$ came in the first week after discharge and $75 \%$ came later on as advised in the symptomatic group. AKP or paraffin poisoning occurs in poor families where it is used most frequently. Ellis et al. 1994 postulated that poisoning occurs because of its resemblance to water and improper storage [21]. These families have financial constrains in buying locked cabinets and are ignorant in allocating of high storage spaces out of reach of children, having childproof containers and away from playing areas. There is also lack of immediate conveyance in some rural areas to reach the hospital in time. It is common for some of the carers to induce vomiting in children in these cases as is local belief, which can be a dangerous as can result in severe aspiration chemical pneumonitis. In our study also about 4 mothers had induced vomiting but fortunately were given good care after admission.

Adding dyes or only selling paraffin in childproof containers would remove the need for country level action and investment as the addition of blue dye to paraffin has significantly reduced these poisonings $[22,23]$. It is advisable for the family to keep these drugs away from children. So it is a challenge for the paediatrician to treat such cases of AKP. No specific antidotes are known. During routine medical checkups at hospitals and clinics pamphlets and small informative cards should be circulated in the community on prevention of poisoning, first aids and life saving measures. Psychology counselling should be given to the children who are intentionally causing AKP and special attention should be paid to the high incidence of poisoning in children all over the world. The medical curriculum should give importance to the field of Clinical toxicology so that these AKPs issues can be treated timely and successfully with the acquired knowledge [24,25].

\section{Conclusion}

Accidental childhood kerosene poisoning is a major public health problem. The awareness of the AKP could reduce the morbidity and mortality rate as prevention of ingestion is the cure. Pharmaceutical drugs and medicines, kerosene, and household chemicals are the main substances responsible for APs as these substances are not stored properly. Parental education is the hall mark in prevention of all APs with due importance to AKP at home. 
Acknowledgement: The authors acknowledge the help of the MRD section of the medical college for their help and support. Also express gratitude to house surgeons, post graduate students, nursing staff, colleagues for their timely help and to Dr Ajith TA, Professor, Biochemistry, Amala Institute of Medical Sciences, Amala Nagar, Thrissur, Kerala, India during the preparation of the manuscript.

\section{Source of Support: Nil \\ Conflict of Interest: None \\ Permission of IRB: Yes}

\section{References}

1. Eddleston M. Patterns and problems of deliberate self-poisoning in the developing world. QJM. 2000 Nov;93(11):715-31.

2. Hyder AA, Wali S, Fishman S, Schenk E. The burden of unintentional injuries among the under-five population in South Asia. Acta Paediatr. 2008 Mar; $97(3) \quad$ : 267-75. doi: $10.1111 /$ j.1651 2227.2008.00670.x.

3. Bronstein AC, Spyker DA, Cantilena LR Jr, Green JL, Rumack BH, Heard SE; American Association of Poison Control Centers. 2007 Annual Report of the American Association of Poison Control Centers' National Poison Data System (NPDS): 25th Annual Report. Clin Toxicol (Phila). 2008 Dec;46(10):9271057. doi: 10.1080/15563650802559632.

4. Lifshitz M, Sofer S, Gorodischer R. Hydrocarbon poisoning in children: a 5-year retrospective study. Wilderness Environ Med. 2003 Summer;14(2):78-82.

5. Singh S, Singhi S, Sood NK, Kumar L, Walia BN. Changing pattern of childhood poisoning (1970-1989): experience of a large north Indian hospital. Indian Pediatr. 1995 Mar;32(3):331-6.

6. Izuora GI, Adeoye A. A seven-year review of accidental poisoning in children at a Military Hospital in Hafr Al Batin, Saudi Arabia. Ann Saudi Med. 2001 Jan-Mar;21(1-2):13-5.

7. Abula $\mathrm{T}$, Wondmikun $\mathrm{Y}$. The pattern of acute poisoning in a teaching hospital, north-west Ethiopia. Ethiop Med J. 2006 Apr;44(2):183-9.

8. Paudyal BP. Poisoning : pattern and profile of admitted cases in a hospital in central Nepal. JNMA J Nepal Med Assoc. 2005 Jul-Sep;44(159):92-6.
9. Binetti R, Costamagna FM, Marcello I. Exponential growth of new chemicals and evolution of information relevant to risk control. Ann Ist Super Sanita. 2008;44(1):13-5.

10. GERARDE HW. Toxicologiccal studies on hydrocarbons. IX. The aspiration hazard and toxicity of hydrocarbons and hydrocarbon mixtures. Arch Environ Health. 1963 Mar;6:329-41.

11. Wasserman GS. Hydrocarbon poisoning. Grit Care Q 1982;4: 33-41.

12. Simmank K, Wagstaff L, Sullivan K, Filteau S, Tomkins A. Prediction of illness severity and outcome of children symptomatic following kerosene ingestion. Ann Trop Paediatr. 1998 Dec;18(4):309-14

13. Wolfe BM, Brodeur AE, Shields JB. The role of gastrointestinal absorption of kerosene in producing pneumonitis in dogs. J Pediatr. 1970 Jun;76(6):867-73.

14. Arena JM. Hydrocarbon poisoning--current management. Pediatr Ann. 1987 Nov;16(11):879-83.

15. Klein BL, Simon JE. Hydrocarbon poisonings. Pediatr Clin North Am. 1986 Apr;33(2):411-9.

16. Nagi NA, Abdulallah ZA. Kerosene poisoning in children in Iraq. Postgrad Med J. 1995 Jul;71(837):41922.

17. Munro SA, van Niekerk A, Seedat M. Childhood unintentional injuries: the perceived impact of the environment, lack of supervision and child characteristics. Child Care Health Dev. 2006 May;32(3):269-79.

18. Akamaguna AI, Odita JC. Radiology of kerosene poisoning in young children. Ann Trop Paediatr. 1983 Jun;3(2):85-8

19. Schwebel DC, Swart D, Simpson J, Hobe P, Hui SK. An intervention to reduce kerosene-related burns and poisonings in low-income South African communities. Health Psychol. 2009 Jul;28(4):493-500. doi: $10.1037 / \mathrm{a} 0014531$.

20. Abu-Ekteish F. Kerosene poisoning in children: a report from northern Jordan. Trop Doct. 2002 Jan;32(1):27-9.

21. Ellis JB, Krug A, Robertson J, Hay IT, MacIntyre U. Paraffin ingestion--the problem. S Afr Med J. 1994 Nov;84(11):727-30. 
22. Fagbule DO, Joiner KT. Kerosene poisoning in childhood: a 6-year prospective study at the University of Ilorin Teaching Hospital. West Afr J Med. 1992 AprJun;11(2):116-21.

23. de Wet B, van Schalkwyk D, van der Spuy J, du Plessis J, du Toit N, Burns D. Paraffin (kerosene) poisoning in childhood--is prevention affordable in South Africa? S Afr Med J. 1994 Nov;84(11):735-8.
24. Khan NU, Fayyaz J, Khan UR, Feroze A. Importance of clinical toxicology teaching and its impact in improving knowledge: sharing experience from a workshop. J Pak Med Assoc. 2013 Nov;63(11):1379-82.

25. Shotar AM. Kerosene poisoning in childhood: a 6year prospective study at the Princess Rahmat Teaching Hospital. Neuro Endocrinol Lett. 2005 Dec;26(6):8358.

\section{How to cite this article?}

Sunilkumar MN, Parvathy VK, Analysis of profile of childhood kerosene poisoning in a tertiary care medical college hospital: Int J Pediatr Res 2016;3(4):214-220.Doi:10.17511/ijpr.2016.i04.02. 